\title{
Optimum Allocation of Objective Color Measurements for Evaluating Fresh Strawberries
}

\author{
Erik J. Sacks ${ }^{1}$ and Douglas V. Shaw \\ Department of Pomology, University of California, Davis, CA 95616 \\ Additional index words. Fragaria $\times$ ananassa, genotype $\times$ environment interaction, sample size
}

\begin{abstract}
Components of variance were estimated for 10 strawberry (Fragaria $\times$ ananassa) color traits to determine their relative importance and to design optimal sampling strategies. The color attributes of $>2000$ fruit from 47 genotypes from the Univ. of California Strawberry Improvement Program were evaluated over three harvest dates (HDs) in one growing season. Measurements were obtained for a moderate number of fruit from each genotype on each date, and two measurements were obtained for each trait on all fruit. Variances for HDs were nonsignificant or small $(0 \%$ to $8 \%$ of the total variance). Genotype $\times$ date variances were highly significant but small $(\leq 6 \%$ of the total) for all color traits except internal hue (14\% of the total). For external color traits, the within-fruit variance was greater than the among-fruit variance $(16 \%$ to $64 \%$ and $0 \%$ to $14 \%$ of the total, respectively). For internal color traits, the among-fruit variance was greater than the within-fruit variance $(20 \%$ to $37 \%$ and $9 \%$ to $19 \%$ of the total, respectively). Obtaining two measurements per fruit for several fruit on one HD is an efficient strategy for characterizing a genotype's fruit color; seven to 22 fruit are needed to estimate a genotype's fruit color within 2 units (Commission Internationale de $L$ 'Eclairage $L * a * b *$ or degrees) with $95 \%$ confidence.
\end{abstract}

The color of fresh strawberries is a highly variable trait in seedling populations and one of the most important traits for selecting commercially acceptable cultivars. The value of objective color measurements for a breeding program depends on their consistency and precision in relevant production environments.

Plant breeders maximize the efficiency of genotypic evaluations by identifying the most important sources of sampling and genotype $\times$ environment interaction variance and by replicating sampling procedures among and within genotypes over the most important sources (Allard, 1960; Comstock and Moll, 1963). The optimum allocation of observations can be determined by repeatedly evaluating a representative population of genotypes over the relevant test environments (Wehner, 1987) from which components of variance can be estimated and compared. In a study that compared clonal representatives of a strawberry seedling population at two locations, Shaw (1991) found that additive $\times$ location and dominance $\times$ location interactions accounted for $0 \%$ to $1 \%$ and $0 \%$ to $12 \%$ of the phenotypic variance for fruit color traits, respectively. Averaging the color values of three fruit per genotype with two measurements per fruit resulted in large error variances, a result suggesting that more extensive sampling could substantially improve the precision of genotypic estimates for strawberry color traits. In this study, we investigated the relative importance of the within-fruit sampling variance, the variation among fruit of a given genotype, and the variation associated with sampling a genotype's fruit on several dates within a growing season in evaluating the fruit color of strawberry genotypes.

\section{Materials and Methods}

Genotypes. A population of 47 strawberry genotypes with a broad range of fruit color was chosen to represent the California germplasm. The study population included six California culti-

Received for publication 28 Dec. 1992. Accepted for publication 28 May 1993. Research from a thesis by E.S. in partial fulfillment of the requirements of an MS in horticulture. We thank Thomas Gradziel, James Harding, and Adel Kader for their editorial assistance. The cost of publishing this paper was defrayed in part by the payment of page charges. Under postal regulations, this paper therefore must be hereby marked advertisement solely to indicate this fact.

${ }^{1}$ Present address: Dept. of Vegetable Crops, Univ. of California, Davis, CA 95616. vars, 30 selections from a previously described seedling population (Shaw, 1991), the parents of the seedling population, and several additional genotypes chosen for their atypical fruit coloration. Selections from the seedling population were chosen for exterior (skin) or interior (flesh) color, or both, that was near the light or dark extremes of the original phenotypic distribution. A uniformly distributed sample rather than a random sample of genotypes was chosen for this study so that the consequences of extreme color values for sampling parameters could be evaluated further. Each genotype was represented by eight to 20 runner plants at the Univ. of California Strawberry Research Facility near Watsonville. Runners were planted on 9 Nov. 1990 and grown as recommended for commercial winter-planted strawberries (Welch, 1989).

Fruit and harvest dates (HDs). Ripe, fully colored strawberries were harvested on 29 Apr., 30 May, and 24 June 1991 (HDs 1, 2, and 3, respectively). Fruit from all runner plants of a given genotype were pooled during harvest, transported to Davis, Calif., in an air-conditioned car, stored at $0 \mathrm{C}$ with $85 \%$ to $90 \%$ relative humidity, and evaluated for color within 4 days of harvest. Damaged and overripe fruit were excluded from the study.

Altogether, 2023 and 2007 fruit were evaluated for external and internal color, respectively. Each genotype was represented by 30 to 55 fruit. The number of fruit per HD ranged from 615 to 705 . Fruit from four genotypes were not available on HD 1 and data for internal-color measurements were also missing for a single genotype from HD 2. Excluding the missing data, the number of fruit per genotype per HD ranged from 2 to 25 and 13 to 15 on HDs 1 and 2, respectively. On HD 3, each genotype was represented by 15 fruit. If $>25$ fruit were available for study on HD 1 or $>15$ fruit were available on HDs 2 and 3, the available fruit were randomly sampled.

Color measurement. Objective measurements in Commission Internationale de L'Eclairage (CIELAB) color space (CIE, 1978) were obtained with a reflectance spectrophotometer (Colormet; Agtron, Reno, Nev.). The instrument used a D65 illuminant and a $45^{\circ}$ normal illuminating and viewing geometry. Hue (h), expressed as an angular measure, and chroma $\left(\mathrm{C}^{*}\right)$ were calculated as follows (CIE, 1978): $\mathrm{h}=\arctan \left(b^{*} / a^{*}\right)$ and $C^{*}=\left(a^{* 2}+b^{* 2}\right)^{1 / 2}$. In CIELAB color space, the minimum perceptible difference for the typical observer is about \pm 1 unit (Instrumar Engineering, 1989), whereas 
differences of about \pm 2 units are typically noticeable (J. Weitz, Minolta, personal communication).

Each fruit was measured for external and internal color. External color was measured on two sides of a fruit that was centered and gently pressed against the instrument's aperture (Fig. 1). Internal color was likewise measured on 2 sides of a longitudinally cut fruit (Fig. 1).

Statistical analysis. Analyses of variance were performed using SAS's (1988) GLM procedure with Type III sums of squares to test for main effects of genotype and date, genotype $\times$ date interaction effects, and differences among fruit nested within genotype and date. Analyses were conducted for 10 dependent variables: external and internal $\mathrm{L}^{*}, \mathrm{a}^{*}, \mathrm{~b}^{*}$, hue, and chroma. Tests assumed a random-effects model and that the genotypes were a representative population.

Components of variance were estimated by equating linear functions of the expected mean squares (Table 1) with experimental mean squares. Repeatabilities (r) for multiple measurements on a single date were estimated as

$$
\mathrm{r}_{\mathrm{F}, \mathrm{R}}=\sigma_{\mathrm{g}}^{2} /\left[\sigma_{\mathrm{g}}^{2}+\sigma_{\mathrm{gd}}^{2}+1 / \mathrm{F} \times \sigma_{\mathrm{f}(\mathrm{gd})}^{2}+1 / \mathrm{FR} \times \sigma_{\mathrm{e}}^{2}\right]
$$

where $\mathrm{F}$ is the number of fruit sampled; $\mathrm{R}$ is the number of observations per fruit (replications); and $\sigma_{\mathrm{g}}^{2}, \sigma_{\mathrm{gd}}^{2}, \sigma_{\mathrm{f(gd})}^{2}$, and $\sigma_{\mathrm{e}}^{2}$ are estimates of the genotype, genotype $\times$ date, fruit within genotype and date, and error variances, respectively. When R measurements per fruit are obtained, the number of fruit (n) necessary to estimate a genotype's mean color trait value for a single date within $\delta$ units (CIELAB or degrees) with $95 \%$ confidence is estimated as (Steel and Torrie, 1980)

$$
\mathrm{n}=1.96^{2}\left[{\sigma_{\mathrm{f}(\mathrm{gd})}^{2}}^{2}+1 / \mathrm{R} \times{\sigma_{\mathrm{e}}^{2}}^{2}\right] / \delta^{2}
$$

\section{Results and Discussion}

Descriptive statistics and significance tests. Ranges for $\mathrm{L}^{*}$, hue, and chroma for the six cultivars included in this study averaged $36 \%$ and $56 \%$ for external and internal color traits $(27 \%$ to $45 \%$ and $46 \%$ to $67 \%$ for individual traits, respectively) of the ranges obtained for the entire population (Table 2). Conversely, ranges for external and internal color traits averaged $97 \%$ (70\% to $136 \%$ ) and $89 \%(73 \%$ to $107 \%)$ of the values reported by Sacks and Shaw (1993) for a related segregating seedling population evalu-

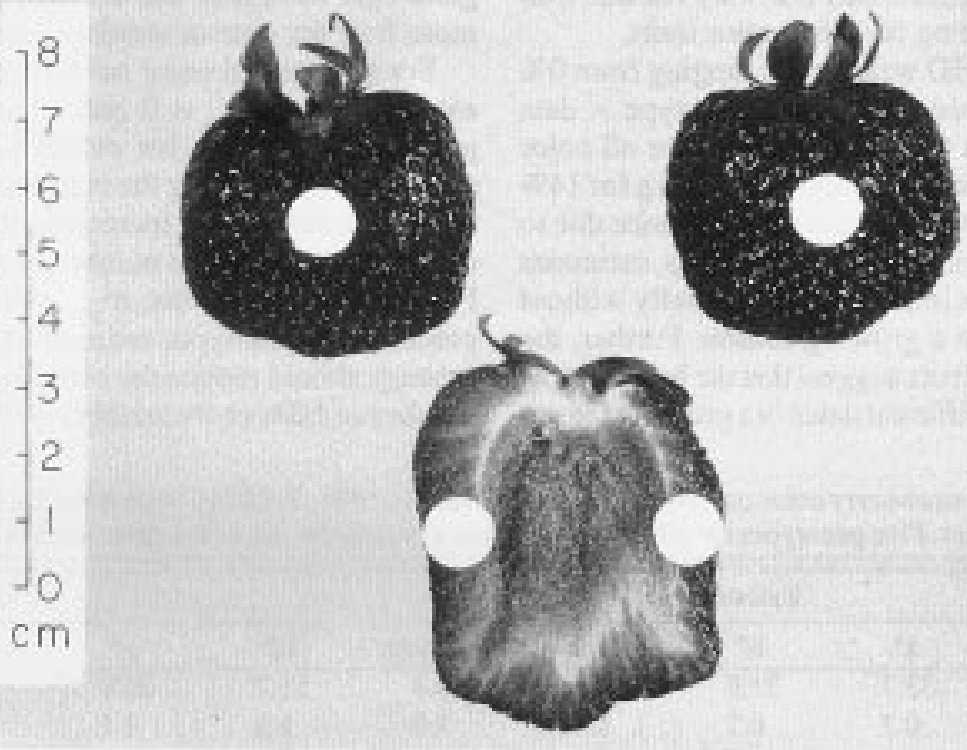

Fig. 1. The size, shape, and locations of the areas measured for color traits are represented by white disks of paper on the fruit surfaces.

\begin{tabular}{|c|c|c|c|}
\hline \multirow[b]{2}{*}{ Source } & \multicolumn{2}{|c|}{$\mathrm{df}$} & \multirow[b]{2}{*}{ Expected mean squares ${ }^{\mathrm{z}}$} \\
\hline & External & Internal & \\
\hline Genotype (G) & 46 & 46 & $\sigma_{\mathrm{e}}^{2}+\mathrm{k}_{1} \sigma_{\mathrm{f}(\mathrm{gd})}^{2}+\mathrm{k}_{2} \sigma_{\mathrm{gd}}^{2}+\mathrm{k}_{3} \sigma^{2}$ \\
\hline Date (D) & 2 & 2 & $\sigma_{\mathrm{e}}^{2}+\mathrm{k}_{1} \sigma_{\mathrm{f}(\mathrm{gd})}^{2(\mathrm{gid})}+\mathrm{k}_{4} \sigma_{\mathrm{gd}}^{2^{\mathrm{g}}}+\mathrm{k}_{5} \sigma^{2}$ \\
\hline $\mathrm{G} \times \mathrm{D}$ & 88 & 87 & $\sigma_{\mathrm{e}}^{2^{\mathrm{e}}}+\mathrm{k}_{1} \sigma_{\mathrm{f}(\mathrm{gd})}^{2^{\mathrm{f}(\mathrm{gd})}}+\mathrm{k}_{6} \sigma_{\mathrm{gd}}^{\mathrm{gd}}$ \\
\hline Fruit $(F)$ within $G$ and $D$ & 1886 & 1871 & $\sigma_{\mathrm{e}}^{2}+\mathrm{k}_{1} \sigma_{\mathrm{f}(\mathrm{gd})}^{2(\mathrm{gd})}$ \\
\hline Error within $\mathrm{F}$ & 2022 & 2006 & $\sigma_{e}^{2}$ \\
\hline
\end{tabular}

Table 1. Form of expected mean squares for analysis of external and internal fruit color traits.

${ }^{\mathrm{z} C o e f f i c i e n t s ~ w e r e ~ e s t i m a t e d ~ u s i n g ~ S A S ' s ~(1988) ~ G L M ~ p r o c e d u r e ~ f r o m ~ T y p e ~ I I I ~ s u m s ~ o f ~ s q u a r e s ~ a s ~ f o l l o w s: ~}$

$\begin{array}{lll} & \text { External } & \text { Internal } \\ \mathrm{k}_{1} & 2.0 & 2.0 \\ \mathrm{k}_{2} & 27.3 & 27.4 \\ \mathrm{k}_{3} & 79.4 & 78.7 \\ \mathrm{k}_{4} & 25.5 & 25.4 \\ \mathrm{k}_{5} & 1155.5 & 1140.2 \\ \mathrm{k}_{6} & 28.5 & 28.5\end{array}$


ated at Watsonville the previous year. Although the results from trials conducted in different years are not directly comparable, the similarity of ranges suggests that the values of traits in our test population are representative of those likely to be encountered in seedling selection programs.

In terms of human perception, differences among color trait means for the three HDs were small (0.4 to 4.8 units over all traits). Differences among means were also small compared with the range of values observed for each of the color traits. External color was slightly darker and internal color was a slightly bluer and more chromatic red as the season progressed (Table 2).

Highly significant differences among genotypes were found for all color traits (Table 3). No significant differences among HDs were found for external $a^{*}, b^{*}$, hue, and chroma and internal $\mathrm{L}^{*}$ (Table 3). However, highly significant differences among HDs were found for external $\mathrm{L}^{*}$ and internal $\mathrm{a}^{*}, \mathrm{~b}^{*}$, hue, and chroma (Table 3 ). Genotype $\times$ date interactions were highly significant for all color traits (Table 3). Highly significant differences among fruit nested within genotypes and dates were found for all color traits except external hue (Table 3).

Components of variance. Differences among genotypes contributed the largest single component of variance for all fruit color traits, except external and internal hue (Table 4). The low genotypic variation found for hue suggests that breeding for this trait may be more difficult than breeding for other color traits.

Variance components due to HD were small, ranging from $0 \%$ to $8 \%$ of the phenotypic variance (Table 4$)$. Genotype $\times$ date interaction variances were small ( $\leq 6 \%$ of the total) for all color traits except internal hue, with the interaction accounting for 14\% of the phenotypic variance (Table 4). Because the variance due to genotype $\times$ date interaction is small for most color traits, estimates of a genotype's fruit color can be improved substantially without sampling on several dates within a growing season. Further, the small date and genotype $\times$ date effects suggest that the breeder may evaluate different genotypes on different dates in a growing season with little sacrifice in selection efficiency.

Among-fruit variation accounted for $0 \%$ to $14 \%$ and $20 \%$ to $37 \%$ of the phenotypic variance for external and internal color traits, respectively (Table 4). When among-fruit variances are large, evaluating more fruit should be an efficient strategy for improving the precision of genotypic estimates for external and internal color traits.

The within-fruit sampling variances were large, ranging from $16 \%$ to $64 \%$ and $9 \%$ to $19 \%$ of the phenotypic variance for external and internal color traits, respectively (Table 4). Thus, increasing the number of observations per fruit should substantially improve the precision of genotypic estimates for external and internal fruit color.

Optimum allocation. The optimum allocation of objective color measurements to observations per fruit, fruit within genotypes, and harvests per growing season is determined by the cost and benefit of a given measurement. The phenotypic variance $\left(\sigma_{p}^{2}\right)$ of a genotypic mean can be estimated as

$$
\sigma_{\mathrm{p}}^{2}=\sigma_{\mathrm{g}}^{2}+\sigma_{\mathrm{gd}}^{2} / \mathrm{D}+\sigma_{\mathrm{f}(\mathrm{gd})}^{2} / \mathrm{DF}+\sigma_{\mathrm{e}}^{2} / \mathrm{DFR}
$$

where $\mathrm{D}, \mathrm{F}$ and $\mathrm{R}$ are the number of HDs, fruit, and observations per fruit, respectively. Thus, the contribution of $\sigma_{e}^{2}, \sigma_{f(g d)}^{2}$, or $\sigma_{g d}^{2}$ to the phenotypic variance can be reduced and the precision of genotypic estimates can be increased by sampling more dates, more fruit per date or obtaining more observations per fruit.

For all external color traits except hue, $\sigma_{\mathrm{e}}^{2}>\sigma_{\mathrm{f}(\mathrm{gd})}^{2}>\sigma_{\mathrm{gd}}^{2}$. For external hue, $\sigma_{\mathrm{f}(\mathrm{gd})}^{2}=0$ and $\sigma_{\mathrm{e}}^{2}>\sigma_{\mathrm{gd}}^{2}$. Thus, the precision of genotypic estimates for external color can be increased most efficiently by reducing the contribution of $\sigma^{2}$. The contribution of $\sigma^{2}$ can be reduced by increasing the number of HDs, the number of fruit per date, or the number of observations per fruit (Eq. [3]). For internal color traits, $\sigma_{\mathrm{f}(\mathrm{gd})}^{2}>\sigma_{\mathrm{e}}^{2}>\sigma_{\mathrm{gd} .}^{2}$ Thus, to increase the precision of genotypic estimates for internal color, the sampling strategy should reduce the contribution of $\sigma_{\mathrm{f}(\mathrm{gd})}^{2}$ by increasing the number of HDs or the number of fruit per date (Eq. [3]).

Table 2. Descriptive statistics for 10 strawberry color traits on three harvest dates in 1991. Statistics were based on genotypic values for 42 genotypes that were common to all three dates. Five genotypes for which no data were available on one of the dates were omitted from the comparison below.

\begin{tabular}{|c|c|c|c|c|c|c|c|c|c|c|}
\hline \multirow{2}{*}{$\begin{array}{l}\text { Harvest } \\
\text { date }\end{array}$} & \multicolumn{5}{|c|}{ External } & \multicolumn{5}{|c|}{ Internal } \\
\hline & $\mathrm{L}^{*}$ & $a^{*}$ & $\mathrm{~b}^{*}$ & Hue & Chroma & $\mathrm{L}^{*}$ & $a^{*}$ & $\mathrm{~b}^{*}$ & Hue & Chroma \\
\hline 1 Mean & 28.2 & 33.7 & 21.9 & 32.4 & 40.4 & 51.7 & 26.9 & 22.6 & 41.5 & 35.4 \\
\hline $\mathrm{SE}$ & 0.7 & 0.7 & 0.7 & 0.4 & 1.0 & 1.2 & 1.1 & 0.5 & 1.0 & 1.1 \\
\hline 2 Mean & 27.1 & 33.2 & 21.5 & 32.1 & 39.8 & 51.9 & 29.9 & 24.4 & 39.9 & 38.6 \\
\hline $\mathrm{SE}$ & 0.7 & 0.9 & 0.9 & 0.5 & 1.2 & 1.2 & 0.9 & 0.5 & 0.5 & 1.0 \\
\hline 3 Mean & 26.9 & 33.4 & 22.2 & 32.5 & 40.3 & 51.3 & 31.1 & 25.4 & 39.7 & 40.2 \\
\hline $\mathrm{SE}$ & 0.8 & 1.0 & 1.0 & 0.6 & 1.4 & 1.1 & 0.8 & 0.4 & 0.4 & 0.9 \\
\hline \multicolumn{11}{|l|}{ All } \\
\hline Mean & 27.4 & 33.5 & 21.9 & 32.3 & 40.1 & 51.6 & 29.3 & 24.1 & 40.4 & 38.1 \\
\hline Range & $17.4-38.7$ & $18.4-42.6$ & $8.6-33.2$ & $24.3-39.7$ & $20.3-53.5$ & $33.2-66.7$ & $7.0-39.3$ & $15.0-31.0$ & $35.5-65.8$ & $16.8-49.6$ \\
\hline
\end{tabular}

Table 3. Results of analysis of variance for 10 strawberry color traits based on 47 genotypes and three harvest dates.

\begin{tabular}{|c|c|c|c|c|c|c|c|c|c|c|}
\hline \multirow[b]{2}{*}{ Source } & \multicolumn{5}{|c|}{ External } & \multicolumn{5}{|c|}{ Internal } \\
\hline & $\mathrm{L}^{*}$ & $a^{*}$ & $b^{*}$ & Hue & Chroma & $\mathrm{L}^{*}$ & $a^{*}$ & $b^{*}$ & Hue & Chroma \\
\hline \multicolumn{11}{|c|}{ Mean squares } \\
\hline Genotype (G) & $1652.8^{* * *}$ & $2248.4^{* *}$ & $2477.3^{* * *}$ & $742.8^{* *}$ & $4408.8^{* *}$ & $4122.7^{* * *}$ & $2411.9^{* * *}$ & $651.6^{* * *}$ & $765.7^{* *}$ & $2798.8^{* * *}$ \\
\hline Date (D) & $590.2^{* *}$ & $61.6^{\mathrm{NS}}$ & $97.2^{\mathrm{NS}}$ & $53.8^{\mathrm{NS}}$ & $96.5^{\mathrm{Ns}}$ & $257.8^{\mathrm{NS}}$ & $4271.7^{* *}$ & $1745.0^{* *}$ & $807.0^{* *}$ & $5652.8^{* * *}$ \\
\hline $\mathrm{G} \times \mathrm{D}$ & $52.3^{* *}$ & $90.3^{* *}$ & $114.7^{* *}$ & $59.2^{* *}$ & $177.5^{* *}$ & $109.9^{* * *}$ & $122.5^{* *}$ & $41.6^{* *}$ & $132.2^{* *}$ & $136.4^{* *}$ \\
\hline Fruit $(\mathrm{F})$ within $\mathrm{G}$ and $\mathrm{D}$ & $12.9^{* *}$ & $18.4^{* * *}$ & $25.0^{* * *}$ & $17.7^{\mathrm{NS}}$ & $35.0^{* * *}$ & $36.7^{* *}$ & $39.9^{* *}$ & $13.2^{* *}$ & $24.8^{* *}$ & $45.8^{* * *}$ \\
\hline Error & 8.5 & 6.9 & 17.8 & 17.7 & 15.9 & 7.0 & 6.8 & 3.6 & 4.7 & 9.0 \\
\hline
\end{tabular}


Table 4. Components of variance ${ }^{\mathrm{z}}$ and proportions of phenotypic variance (in parentheses) for 10 strawberry color traits.

\begin{tabular}{|c|c|c|c|c|c|c|c|c|c|c|}
\hline \multirow[b]{2}{*}{ Parameter } & \multicolumn{5}{|c|}{ External } & \multicolumn{5}{|c|}{ Internal } \\
\hline & $\mathrm{L}^{*}$ & $a^{*}$ & $\mathrm{~b}^{*}$ & Hue & Chroma & $\mathrm{L}^{*}$ & $a^{*}$ & $b^{*}$ & Hue & Chroma \\
\hline \multicolumn{11}{|c|}{ Components of variance and proportions of phenotypic variance } \\
\hline$\sigma_{g}^{2}$ & $\begin{array}{c}20.2 \\
(0.62)\end{array}$ & $\begin{array}{c}27.2 \\
(0.64)\end{array}$ & $\begin{array}{c}29.8 \\
(0.55)\end{array}$ & $\begin{array}{c}8.6 \\
(0.31)\end{array}$ & $\begin{array}{c}53.4 \\
(0.64)\end{array}$ & $\begin{array}{c}51.0 \\
(0.68)\end{array}$ & $\begin{array}{c}29.1 \\
(0.49)\end{array}$ & $\begin{array}{c}7.8 \\
(0.42)\end{array}$ & $\begin{array}{c}8.1 \\
(0.30)\end{array}$ & $\begin{array}{r}33.9 \\
(0.49)\end{array}$ \\
\hline$\sigma_{\mathrm{d}}^{2}$ & $\begin{array}{c}05 \\
(0.01)\end{array}$ & $\begin{array}{c}0.0 \\
(0.00)\end{array}$ & $\begin{array}{c}0.0 \\
(0.00)\end{array}$ & $\begin{array}{c}0.00 \\
(0.00)\end{array}$ & $\begin{array}{c}-0.1 \\
(0.00)\end{array}$ & $\begin{array}{c}0.1 \\
(0.00)\end{array}$ & $\begin{array}{c}3.6 \\
(0.06)\end{array}$ & $\begin{array}{c}1.5 \\
(0.08)\end{array}$ & $\begin{array}{c}0.6 \\
(0.02)\end{array}$ & $\begin{array}{c}4.8 \\
(0.07)\end{array}$ \\
\hline$\sigma_{g d}^{2}$ & $\begin{array}{c}1.4 \\
(0.04)\end{array}$ & $\begin{array}{c}2.5 \\
(0.06)\end{array}$ & $\begin{array}{c}3.1 \\
(0.06)\end{array}$ & $\begin{array}{c}1.5 \\
(0.05)\end{array}$ & $\begin{array}{c}5.0 \\
(0.06)\end{array}$ & $\begin{array}{c}2.6 \\
(0.03)\end{array}$ & $\begin{array}{c}2.9 \\
(0.05)\end{array}$ & $\begin{array}{c}1.0 \\
(0.05)\end{array}$ & $\begin{array}{c}3.8 \\
(0.14)\end{array}$ & $\begin{array}{c}3.2 \\
(0.05)\end{array}$ \\
\hline$\sigma_{\mathrm{f}(\mathrm{gd})}^{2}$ & $\begin{array}{c}2.2 \\
(0.07)\end{array}$ & $\begin{array}{c}5.7 \\
(0.14)\end{array}$ & $\begin{array}{c}3.6 \\
(0.07)\end{array}$ & $\begin{array}{c}0.00 \\
(0.00)\end{array}$ & $\begin{array}{c}9.6 \\
(0.11)\end{array}$ & $\begin{array}{c}14.8 \\
(0.20)\end{array}$ & $\begin{array}{c}16.6 \\
(0.28)\end{array}$ & $\begin{array}{c}4.8 \\
(0.26)\end{array}$ & $\begin{array}{c}10.0 \\
(0.37)\end{array}$ & $\begin{array}{r}18.4 \\
(0.27)\end{array}$ \\
\hline$\sigma_{\mathrm{e}}^{2}$ & $\begin{array}{c}8.5 \\
(0.26)\end{array}$ & $\begin{array}{c}6.9 \\
(0.16)\end{array}$ & $\begin{array}{c}17.8 \\
(0.33)\end{array}$ & $\begin{array}{c}17.7 \\
(0.64)\end{array}$ & $\begin{array}{c}15.9 \\
(0.19)\end{array}$ & $\begin{array}{c}7.0 \\
(0.09)\end{array}$ & $\begin{array}{c}6.8 \\
(0.12)\end{array}$ & $\begin{array}{c}3.6 \\
\left(\begin{array}{ll}0 & 19\end{array}\right)\end{array}$ & $\begin{array}{c}4.7 \\
(0.17)\end{array}$ & $\begin{array}{c}9.0 \\
(0.13)\end{array}$ \\
\hline \multicolumn{11}{|c|}{ Repeatabilities $^{y}$ and $n^{x}$ for $95 \%$ confidence } \\
\hline$r_{1,1}$ & 0.63 & 0.64 & 0.55 & 0.31 & 0.64 & 0.68 & 0.53 & 0.45 & 0.30 & 0.53 \\
\hline$r_{1,2}$ & 0.72 & 0.70 & 0.66 & 0.46 & 0.70 & 0.71 & 0.56 & 0.51 & 0.33 & 057 \\
\hline$r_{5,2}$ & 0.88 & 0.86 & 0.84 & 0.73 & 0.86 & 0.89 & 0.81 & 0.77 & 0.56 & 0.81 \\
\hline$r_{10,2}$ & 0.91 & 0.89 & 0.87 & 0.79 & 0.89 & 0.92 & 0.86 & 0.82 & 0.62 & 0.86 \\
\hline $\mathrm{n}$ & 7 & 9 & 12 & 9 & 17 & 18 & 20 & 7 & 12 & 22 \\
\hline
\end{tabular}

${ }^{\mathrm{z}}$ Small negative components were interpreted as zero.

${ }^{\mathrm{y}} \mathrm{r}_{\mathrm{F}, \mathrm{R}}=$ Repeatabilities for several measurements on a single date, where $\mathrm{F}$ is the number of fruit sampled and $\mathrm{R}$ is the number of observations per fruit (replications).

'When two observations per fruit are obtained, $\mathrm{n}$ is the number of fruit necessary to estimate a genotype's mean color trait value for one harvest date within 2 units (CIELAB or degrees) with $95 \%$ confidence.

Sampling several fruit from each genotype on a single date will improve efficiency for external and internal color traits. Moreover, sampling several fruit on a single date will often be easier than sampling on several dates or obtaining many random and unbiased measurements from a single fruit. Sampling on several dates is the least desirable option because it is likely to be the most costly. Further, the small amount of genotype $\times$ date variation suggests that the benefits of sampling fruit on several HDs would be negligible unless harvesting on more than one date would be necessary to obtain sufficient fruit. Although sampling several fruit will be more efficient for external and internal color traits than obtaining several measurements for each fruit, more than one measurement for each fruit may be needed to avoid sampling bias. Fruit surfaces often receive uneven exposure to sunlight, especially when fruit are wedge-shaped, and, as with apples (Malus domestica Borkh.) (Gross, 1987), the side of the fruit that faces the light is typically more colored than the side that faces the plant. Measuring the entire surface of strawberries may prove to be an effective technique for reducing within-fruit sampling variance and avoiding sampling bias. Francis (1970) suggests that the color of a cranberry's (Vaccinium macrocarpon Ait.) entire surface can be measured with the use of a spinner, i.e., a device that spins the fruit in front of a fixed color-measuring instrument. To avoid sampling bias, we recommend measuring external and internal color traits on at least two opposite sides per fruit. In general, obtaining two observations per fruit for several fruit on one HD is an efficient strategy for determining a genotype's fruit color.

Comparison of repeatabilities (Eq. [1]) for single measurements with those for several measurements demonstrates that sampling multiple fruit on one HD with two observations per fruit is an efficient strategy for all color traits (Table 4). In a population with less genotypic variation than ours, the magnitude of the repeatability would be smaller but the gain in precision from each additional measurement would be greater. Although estimates of repeatability depend on the $\sigma_{\mathrm{g}}^{2}$ of the population studied, estimates of $\sigma_{\mathrm{e}}^{2}$ and $\sigma_{\mathrm{f}(\mathrm{gd})}^{2}$ from this study should be valid for other strawberry populations, assuming that the range of variation is similar to ours and that scale interactions not evaluated here are minimal. Genotype $\times$ date interaction effects may be specific to the population evaluated as well, but the small $\sigma^{2}{ }_{g d}$ values estimated for the broad range of genotypes included in our sample suggest that the contribution of such interactions to the phenotypic variances in other populations will be small.

An alternative to comparing repeatabilities for different sampling distributions is to estimate the number of samples required to obtain a previously defined confidence level. When two observations per fruit are obtained, the number of fruit necessary to estimate a genotype's mean color trait value for a single HD within 2 units (CIELAB or degrees) with $95 \%$ confidence is given in Table 4. Estimates of $n$ (Eq. [2]) for the color traits range from seven to 22 fruit (Table 4).

Although color traits are highly variable in experimental strawberry populations, genotypic values appear stable over many of the environmental factors that affect cultivar selection decisions. Interactions between genetic effects and test location are small (Shaw, 1991), and the fruit color of genotypes is stable during postharvest storage (Sacks and Shaw, 1993). With the above citations, our current results suggest that the fruit color of strawberry genotypes can be evaluated efficiently with one HD and a moderate number of fruit per genotype.

\section{Literature Cited}

Allard, R.W. 1960. Principles of plant breeding. Wiley, New York. Commission Internationale de L'Eclairage (CIE). 1978. Recommendations on uniform color spaces-Color-difference equations, psychometric color terms. CIE, Paris. Publ. 15, Suppl. 2.

Comstock, R.E. and R.H. Moll. 1963. Genotype-environment interactions, p. 164-194. In: W.D. Hanson and H.F. Robinson (eds.). Statistical genetics and plant breeding. Natl. Acad. Sci. Natl. Res. Council, Washington, D.C. Publ. 982. 
Francis, F.J. 1970. Color measurement in plant breeding. HortScience 5:102-106.

Gross, J. 1987. Pigments in fruits. Academic Press, San Diego. Instrumar Engineering. 1989. Colormet user's manual. Instrumar Eng. Sacks, E.J. and D.V. Shaw. 1993. Color change in fresh strawberry fruit of seven genotypes stored at 0C. HortScience 28:209-210.

SAS Institute. 1988. SAS/STAT users guide. release 6.03. SAS Institute, Cary, N.C.
Shaw, D.V. 1991. Genetic variation for objective and subjective measures of fresh fruit color in strawberries. J. Amer. Soc. Hort. Sci. 116:894-898. Steel, R.G. and J.H. Torrie. 1980. Principles and procedures of statistics. 2nd ed. McGraw-Hill, San Francisco.

Wehner, T.C. 1987. Efficient methods for testing vegetable cultivars. HortScience 22:1220-1223.

Welch, N. 1989. Strawberry production in California. Univ. of California Coop. Ext. Lflt. 2959. 